\title{
Recurrent Cervical Mucinous Adenocarcinoma, Endocervical Type
}

National Cancer Institute

\section{Source}

National Cancer Institute. Recurrent Cervical Mucinous Adenocarcinoma, Endocervical

Type. NCI Thesaurus. Code C153573.

The reemergence of cervical mucinous adenocarcinoma, endocervical type after a period of remission. 